\title{
Effects of non-uniform fluid saturation distribution on pressure transient analysis
}

\author{
E. Nikjoo $\cdot$ A. Hashemi
}

Received: 6 December 2011/ Accepted: 7 July 2012/Published online: 28 July 2012

(c) The Author(s) 2012. This article is published with open access at Springerlink.com

\begin{abstract}
Variations of fluid saturation in formation induce unusual trends in pressure transient data, which may cause ambiguities in well test interpretations. Nevertheless, uniform saturation distribution is a common assumption applied in all multiphase well test analysis methods and the effects of fluids saturation changes have not been taken into account in all these approaches. We present a theoretical model which includes non-uniform fluid saturation in pressure transient formulation. The application of the developed model is demonstrated using a simulation of a reservoir containing non-uniform oil and water saturations in the initial condition. This model provides a basis for better interpretation of unusual pressure transient behavior affected by non-uniform saturation distribution.
\end{abstract}

Keywords Well test - Pressure derivative - Fluid saturation · Mobility · Non-uniform distribution

\section{List of symbols}

$C_{\mathrm{t}} \quad$ Total compressibility $\left(\mathrm{ps}^{-1}\right)$

$r_{\mathrm{i}} \quad$ Radius of investigation (ft)

$\lambda_{\mathrm{t}} \quad$ Total mobility (md/cp)

$q_{\mathrm{t}} \quad$ Total flow rate (bbl/day)

$q_{\mathrm{o}} \quad$ Oil flow rate (bbl/day)

$q_{\mathrm{w}} \quad$ Water flow rate (bbl/day)

$k_{\mathrm{o}} \quad$ Effective oil permeability (md)

$k_{\mathrm{w}}$ Effective water permeability (md)

\section{E. Nikjoo $(\square)$}

Department of Petroleum Engineering, Science and Research Branch, Islamic AZAD University, Tehran, Iran

e-mail: ehsan.nikjoo@gmail.com

A. Hashemi

Petroleum University of Technology, Ahwaz, Iran

e-mail: a.hashemi@ put.ac.ir $k \quad$ Permeability (md)

$H \quad$ Thickness (ft)

$\mu_{\mathrm{o}} \quad$ Oil viscosity (cp)

$\mu_{\mathrm{w}} \quad$ Water viscosity (cp)

$r_{\mathrm{e}} \quad$ Reservoir radius (ft)

$r_{\mathrm{w}} \quad$ Well bore radius ( $\mathrm{ft}$ )

$P_{\mathrm{wf}} \quad$ Bottom hole following pressure (ft)

$P_{\mathrm{e}} \quad$ Outer pressure (ft)

$T \quad$ Time (h)
Subscripts
O Oil
G Gas
W Water
T Total
I Initial

\section{Introduction}

In order to simplify the diffusivity equation which is the governing equation for all well test analysis methods several assumptions such as homogenous reservoir, single layer and single-phase liquid flow, etc. have been defined. However, in reality, a period of time after wells start production, other fluids will be observed and therefore the traditional well test analysis techniques no longer will be applied.

In multiphase well test analysis, three methods have been presented in the literature. The first and most widely used method has been introduced by Perrine (1956) and Martine (1959) known as pressure approach. The method is a modification of single-phase approach. An equivalent liquid flow rate is considered, and the analysis methods of oil wells are applied. The applicability of Perrine's method under different situations and scenarios was studied by several

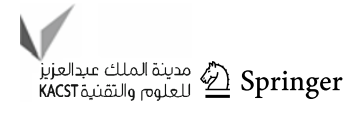


researchers (Weller 1966; Kazemi 1975; Raghavan 1989; Ayan and Lee 1986). Chu et al. (1986) examined the sensitivity of pressure approach under the conditions that the horizontal and vertical saturation gradients exist. They concluded that the reservoir parameters can be calculated with high accuracy by Perrine method when the fluids saturation change in vertical direction, however the well test data should be interpreted with care in the presence of horizontal saturation gradient in reservoirs. Other methods have been presented, using multiphase pseudo-pressure (Raghavan 1976) and pressure squared (Al-Khalifah 1988; Al-Khalifah et al. 1987). Among the three mentioned methods, only the Perrine's method has been widely used in industry due to its simplicity.

Thompson and Reynolds (1997) defined a theoretical expression for pressure derivative in a radially heterogeneous reservoir under multiphase flow condition. They showed that the pressure derivative which is observed at the well bore reflects a weighted harmonic average permeability over the radial extent of the reservoir. In addition, the investigation of multiphase flow effects on the well test analysis in the studies of Raghavan (2010) and Zheng and $\mathrm{Xu}$ (2010) has been extended. Although the considerable researches dealing with multiphase well test analysis can be found in the literature, due to complicated nature of multiphase fluids there are still many ambiguities in this subject especially in the behavior of pressure and pressure derivative data on semi-log and log-log plots used in all well test analysis methods.

In this study, we examined the influences of non-uniform saturation distribution on the analysis and interpretation of pressure and pressure derivative curves. For this purpose, we developed a theoretical model based on Thompson and Reynolds (1997) equation which represents the pressure derivative that is observed at the wellbore as well as the effects on semi log analysis. The theoretical model applications are demonstrated using a simulation in the reservoir which is filled by oil and water with the variety of saturations at the initial condition. This model provides a basis for a better understanding of the conclusions derived by numerical results as well as new insight for interpretation of pressure transient behavior affected by non-uniform saturation distribution.

\section{Theory}

Isothermal multiphase flow in a homogenous reservoir is described by a system of Darcy's equation that represents conservation of mass of oil and water components in black oil systems. By ignoring capillary pressure and gravity effects, the total flow rate at any point in the reservoir can be expressed by the following equation: $q_{\mathrm{t}}(r, t)=q_{\mathrm{o}}(r, t)+q_{\mathrm{w}}(r, t)=2 \pi k h r \lambda_{\mathrm{t}}(r, t) \frac{\partial p}{\partial r}$

where $\lambda_{t}$ is total mobility of oil-water system defined as:

$\lambda_{\mathrm{t}}(r, t)=\frac{k_{\mathrm{ro}}}{\mu_{\mathrm{o}}}+\frac{k_{\mathrm{rw}}}{\mu_{\mathrm{w}}}$

where $k_{\mathrm{ro}}, k_{\mathrm{rw}}, \mu_{\mathrm{o}}, \mu_{\mathrm{w}}$ are relative permeability to oil, relative permeability to water, oil viscosity, and water viscosity, respectively. Integration of Eq. 1 results

$\int_{r_{\mathrm{w}}}^{r_{\mathrm{e}}} \frac{\partial p}{\partial r} \mathrm{~d} r=\frac{1}{2 \pi k h} \int_{r_{\mathrm{w}}}^{r_{\mathrm{e}}} \frac{q_{\mathrm{t}}(r, t)}{r \lambda_{\mathrm{t}}(r, t)} \mathrm{d} r$

Using bounded outer boundary condition for the reservoir:

$\lim _{r \rightarrow r_{\mathrm{e}}} p\left(r_{\mathrm{e}}, t\right)=p_{\mathrm{e}}$

The final solution obtained as:

$\Delta p_{\mathrm{wf}}(t)=P_{\mathrm{e}}-P_{\mathrm{wf}}(t)=\frac{1}{2 \pi k h} \int_{r_{\mathrm{w}}}^{r_{\mathrm{e}}} \frac{q_{\mathrm{t}}(r, t)}{r \lambda_{\mathrm{t}}(r, t)} \mathrm{d} r$

Taking the derivative of Eq. 5 with respect to the natural logarithm of time, the following expression for pressure derivative is obtained:

$$
\begin{aligned}
\frac{\mathrm{d} \Delta p_{\mathrm{wf}}(t)}{\mathrm{d} \ln t}=\frac{1}{2 \pi k h}\left[\int_{r_{\mathrm{w}}}^{r_{\mathrm{e}}} \frac{1}{r \lambda_{\mathrm{t}}(r, t)} \frac{\partial q_{\mathrm{t}}(r, t)}{\partial \ln t}\right. \\
\left.+\int_{r_{\mathrm{w}}}^{r_{\mathrm{e}}} \frac{q_{\mathrm{t}}}{r \lambda_{\mathrm{t}}^{2}(r, t)} \frac{\partial \lambda_{\mathrm{t}}(r, t)}{\partial \ln t}\right] \mathrm{d} r
\end{aligned}
$$

Equation 6 can also be rearranged as:

$$
\begin{aligned}
\frac{\partial p_{\mathrm{wf}}}{\partial \ln (t)}=\frac{\partial p_{\mathrm{e}}}{\partial \ln (t)}-\frac{1}{2 \pi k h}\left[\int_{r_{\mathrm{w}}}^{r_{\mathrm{e}}} \frac{1}{r \lambda_{\mathrm{t}}(r, t)} \frac{\partial q_{\mathrm{t}}(r, t)}{\partial \ln t}\right. \\
\left.+\int_{r_{\mathrm{w}}}^{r_{\mathrm{e}}} \frac{q_{\mathrm{t}}}{r \lambda_{\mathrm{t}}^{2}(r, t)} \frac{\partial \lambda_{\mathrm{t}}(r, t)}{\partial \ln t}\right] \mathrm{d} r
\end{aligned}
$$

Equation 6 indicates that the pressure derivative observed at the wellbore is affected by total mobility in the regions where flow rate and total mobility change rapidly with time. At steady state or pseudo-steady state conditions, flow rate approaches a constant value and its variation with time vanishes, i.e., $\frac{\partial q_{\mathrm{t}}(r, t)}{\partial \ln t} \rightarrow 0$, hence Eq. 6 simplifies to:

$\frac{\mathrm{d} \Delta p_{\mathrm{wf}}(t)}{\mathrm{d} \ln t}=\frac{1}{2 \pi k h}\left[\int_{r_{\mathrm{w}}}^{r_{\mathrm{e}}} \frac{q_{\mathrm{t}}}{r \lambda_{\mathrm{t}}^{2}(r, t)} \frac{\partial \lambda_{\mathrm{t}}(r, t)}{\partial \ln \mathrm{t}}\right] \mathrm{d} r$

Equation 8 could also be rearranged as: 
Table 1 Reservoir and fluid properties

\begin{tabular}{ll}
\hline Well radius, $\mathrm{ft}(\mathrm{m})$ & $0.3(0.091)$ \\
External radius, $\mathrm{ft}(\mathrm{m})$ & $1,500(457.2)$ \\
Porosity, fraction & 0.22 \\
Reservoir thickness, $\mathrm{ft}(\mathrm{m})$ & $100(30.48)$ \\
Connate water saturation, fraction & 0.215 \\
Initial water saturations, fraction & 0.2 and 0.5 \\
Initial reservoir pressure, psi $(\mathrm{MPa})$ & $5,000(35.5)$ \\
Absolute permeability, $\mathrm{md}\left(\mu \mathrm{m}^{2}\right)$ & $172(0.18)$ \\
Flow rate, bbl/day $\left(\mathrm{m}^{3} / \mathrm{s}\right)$ & $1,000(0.00184)$ \\
Oil viscosity, $(\mathrm{mPa} \mathrm{s})$ & 1 \\
Water viscosity, $\left(\mathrm{mPa} \mathrm{s}^{2}\right)$ & 0.5
\end{tabular}

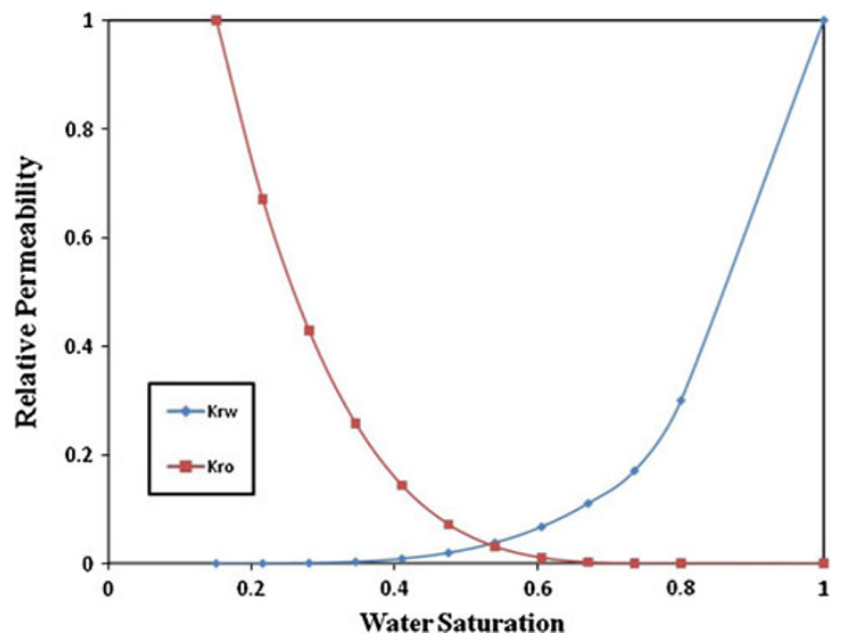

Fig. 1 Relative permeability curve used in this study

$\mathrm{d} \Delta p_{\mathrm{wf}}(t)=\left(\frac{1}{2 \pi k h}\left[\int_{r_{\mathrm{w}}}^{r_{\mathrm{e}}} \frac{q_{\mathrm{t}}}{r \lambda_{\mathrm{t}}^{2}(r, t)} \frac{\partial \lambda_{\mathrm{t}}(r, t)}{\partial \ln t}\right]\right) \mathrm{d} \ln t$

After rearrangement, pressure derivative relation for bounded reservoirs at pseudo-steady state condition results: $\frac{-\mathrm{d} \Delta p_{\mathrm{wf}}(t)}{\mathrm{d} \ln t}=\frac{1}{2 \pi k h}\left[\int_{r_{\mathrm{w}}}^{r_{\mathrm{e}}} \frac{q_{\mathrm{t}}}{r \lambda_{\mathrm{t}}^{2}(r, t)} \frac{\partial \lambda_{\mathrm{t}}(r, t)}{\partial \ln t}\right] \mathrm{d} r$

Equations 8, 9, 10 suggest that at steady state or pseudosteady state conditions, temporal wellbore pressure derivative and bottom-hole pressure variations depend only on total mobility in the region of sudden total mobility change.

\section{Exemplary case}

We present our model in a hypothetical homogenous reservoir that is filled with slightly compressible oil and water. The reservoir is assumed to be at initial pressure equilibrium condition. We also assumed a line-source wellbore located at the center of a cylindrical reservoir which is bounded at the reservoir boundary. Reservoir and fluid properties are summarized in Table 1 and Fig. 1.

We used a non-uniform fluid saturation as illustrated in Fig. 2. Initial water saturation is assumed to be $20 \%$ for a radial distance of $140 \mathrm{ft}$ around the wellbore and the rest of reservoir $\left(r_{\mathrm{e}}=1,500 \mathrm{ft}\right)$ is saturated with $50 \%$ water.

A black oil commercial simulator ECLIPSE 100 Version (2005) was used to design and generate build-up and draw-down tests in the reservoir under consideration moreover, the obtained pressure transient data for each case were analyzed by a well test analysis software Saphir 4.02 Version (2004). Figure 3 shows the plot of the flow rate versus radial distance at different times under a constant flow rate of $500 \mathrm{RB} / \mathrm{D}$. This figure was obtained by inverting the analytical solution for single-phase flow in a multi-composite reservoir using Stefhest algorithm (Stehfest 1970). Note in Fig. 3 that flow rate approaches a constant value at later time. Using relative permeability data given in Fig. 1 and fluid properties in Table 1, total mobility as a function of water saturation is plotted in Fig. 4.
Fig. 2 Initial water saturation profile

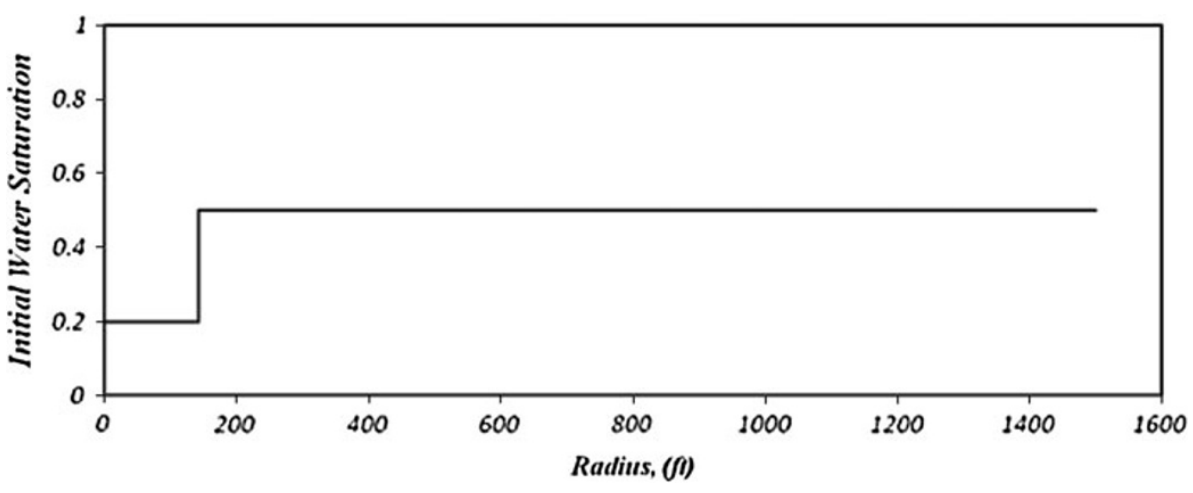




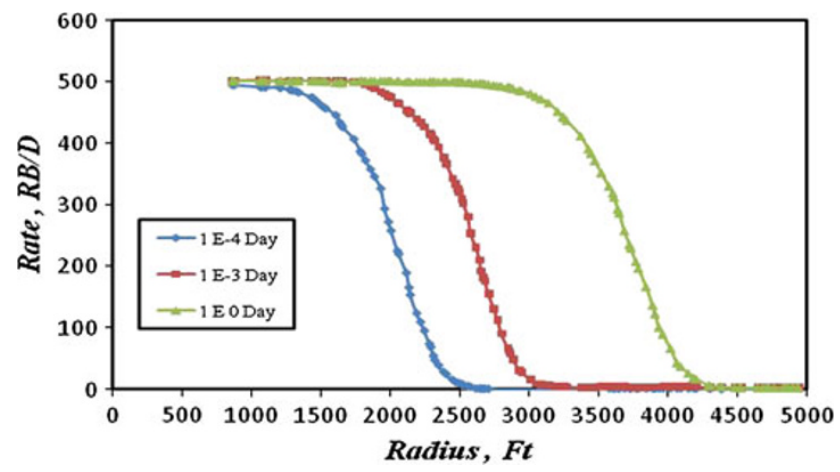

Fig. 3 Rate versus radial distance at different times

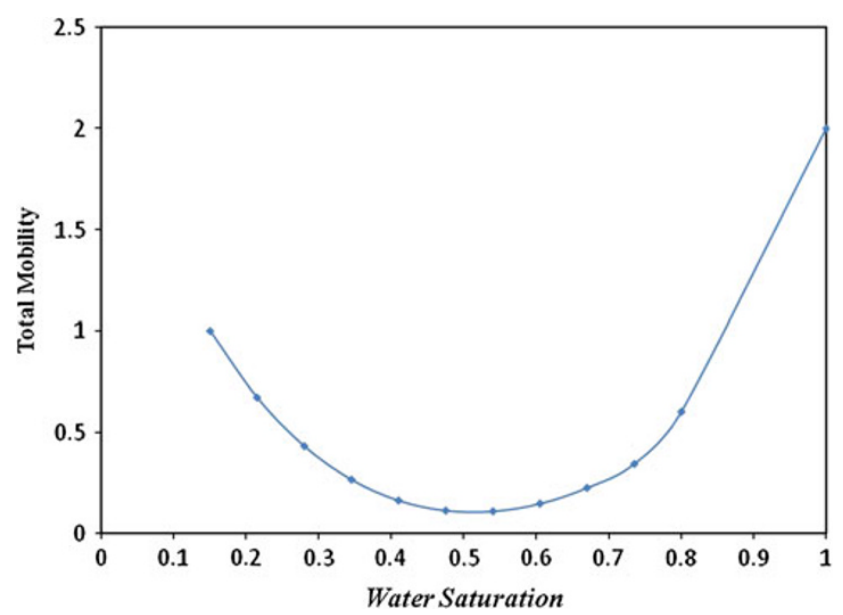

Fig. 4 Total mobility versus water saturation

\section{Pressure draw-down test}

Semi-log analysis

In this section, we present the effects of non-uniform fluid saturation distribution on semi-log pressure plots. Figure 5 shows a semi-log plot of a draw-down test for production time of 50 days. It shows that bottom-hole pressure (BHP) deviates from straight line after about $0.1 \mathrm{~h}$. At the first glance, this deviation and sharp decline might be considered as a reminiscence of boundary effects. Another hypothesis is that, this effect could also be because of the fluid saturation variation as illustrated in Fig. 2 and consequently total mobility variation as shown in Fig. 4. Figure 4 illustrates this point that by increasing water saturation from 0.2 to 0.5 , the total mobility of the reservoir will be decreased from 115 to 20 .

According to Eq. 10, the slope of a semi-log plot in draw-down test is inversely proportional to total mobility in the region where total mobility changes with time. (Note to minus sign in the left hand side term of this equation). As a result of the reduction in the reservoir total mobility (see Fig. 4), the reduction of the slope in semi-log plot depends on the magnitude of total mobility change in the reservoir. We calculated the time in which the effect of pressure disturbance reaches the second region where reservoir water saturation changes from 0.2 to 0.5 that leads to drastic reduction of the total mobility. Using Eq. 11 describing radius of investigation in the reservoir, this time is calculated as $0.1 \mathrm{~h}$

$t=\frac{948 \phi C_{\mathrm{t}} r_{\mathrm{i}}^{2}}{\lambda_{\mathrm{t}}}$

which perfectly coincides with the point of sudden decline in pressure draw-down curve as marked in Fig. 5. In Eq. $11, \phi$ is porosity, $C_{\mathrm{t}}$ is the total compressibility, $r_{\mathrm{i}}$ is the radius of investigation, and $\lambda_{t}$ is total mobility.

Pressure derivative analysis

Equation 8 suggests that pressure derivative at the wellbore is a function of total mobility in the regions with sudden mobility change. Figure 6 shows the pressure derivative curve for the draw-down test for 50 days of production. Pressure derivative data show a declining section, followed
Fig. 5 Draw-down test for 50 days of production

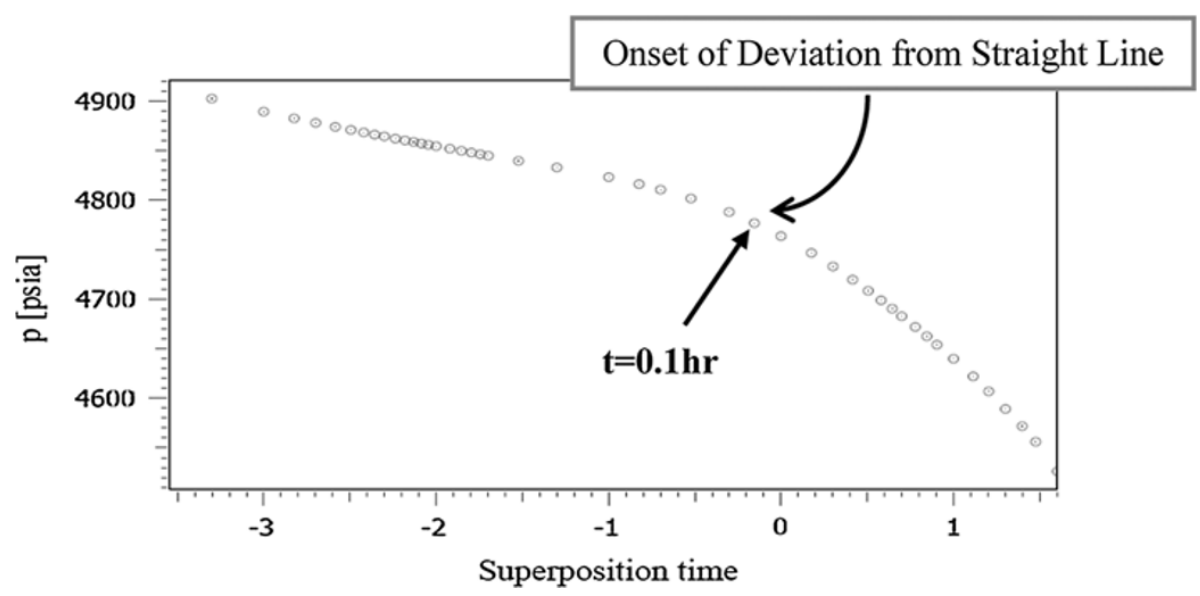




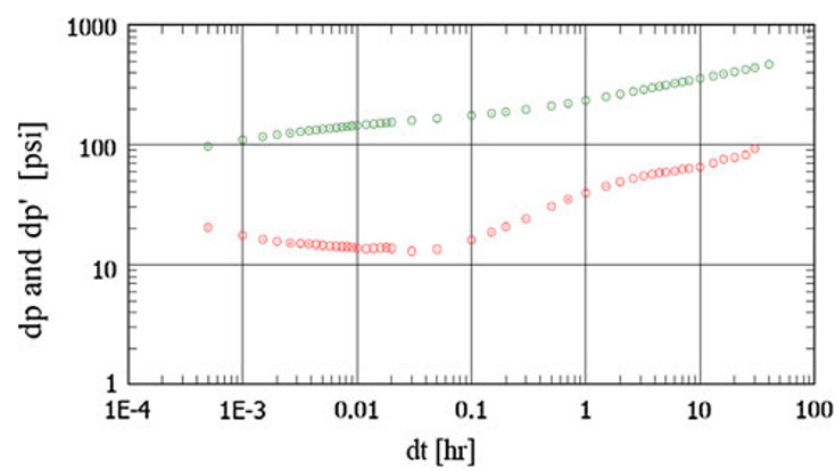

Fig. 6 Pressure derivative plot for draw-down test after 50 days of production

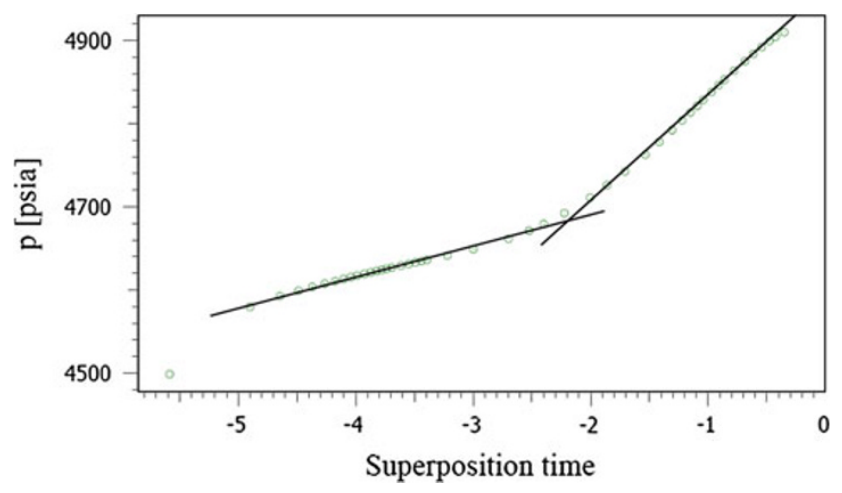

Fig. 7 Build-up test after 50 days of production

Table 2 Results summary from Horner plot analysis

\begin{tabular}{lcccccc}
\hline Parameters & \multicolumn{2}{c}{ First region } & & \multicolumn{2}{c}{ Second region } \\
\cline { 2 - 3 } \cline { 6 - 7 } \cline { 6 - 7 } & Estimated & Actual & & Estimated & Actual \\
\hline Oil mobility (md/cp) & 118.67 & 119.8 & & 11.5 & 7.5 \\
Water mobility (md/cp) & 0.183 & 0.2 & & 6.49 & 13.5 \\
Total mobility (md/cp) & 118.853 & 120 & & 18.981 & 20 \\
\hline
\end{tabular}

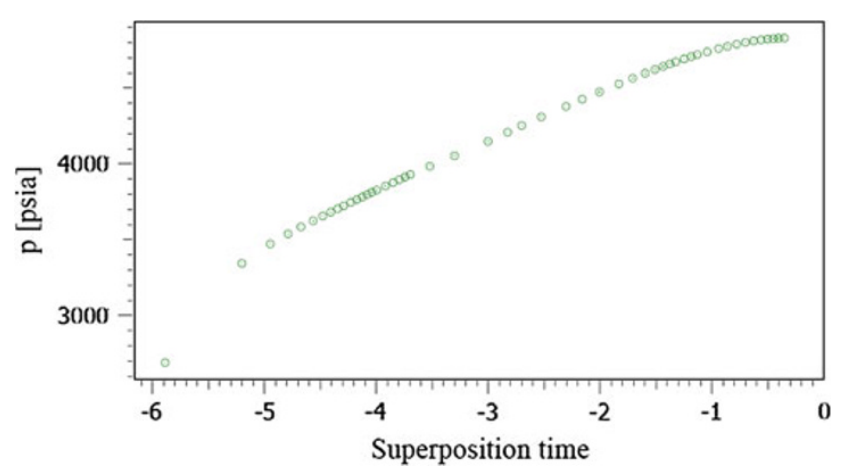

Fig. 8 Build-up test after 100 days of production

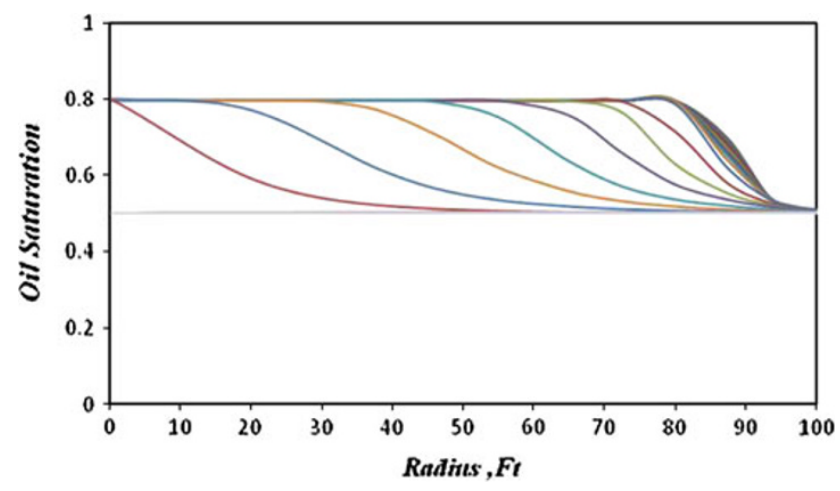

Fig. 9 Oil saturation variation with production time

by a plateau (zero slope) indicating radial flow, an increasing section followed by another plateau, and final increase indicating closed boundary effects. It is evident that the slope of the pressure derivative curve in Fig. 6 changes at about $0.1 \mathrm{~h}$, which is same as we found from BHP data (cf. Fig. 5). This is the time when pressure disturbance feels abrupt saturation variation (0.2-0.5), and consequently mobility variation from 115 to 20 . Equation 8 and this example suggest an increase in pressure derivative when pressure wave feels abrupt total mobility reduction. In addition, it can be observed from the Fig. 6 that the pressure difference (dp) increases during the period. It is possible to justify this condition using Eq. 9 in which pressure difference is inversely proportional to total mobility. Therefore, the delta of pressure change would rise as a result of mobility reduction from 115 to 20 .

\section{Pressure build-up test}

Horner plot

Figure 7 shows the Horner's plot of a build-up test after 50 days of production. There are two distinct regions in

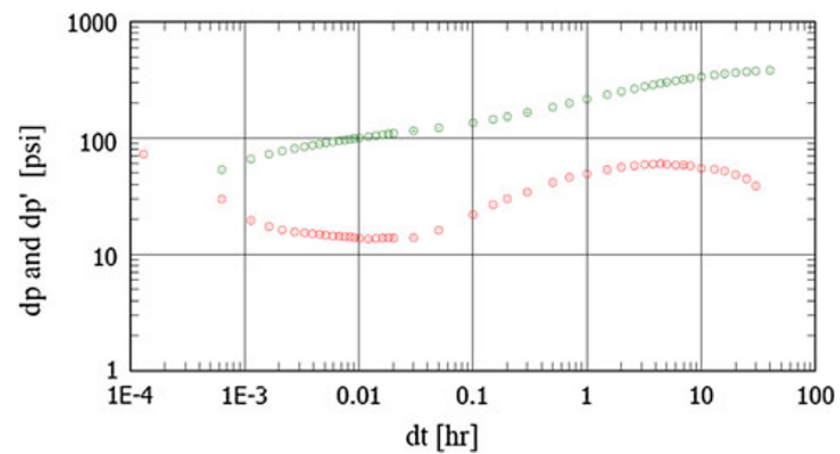

Fig. 10 Pressure and pressure derivative plots for build-up test after 50 days of production 


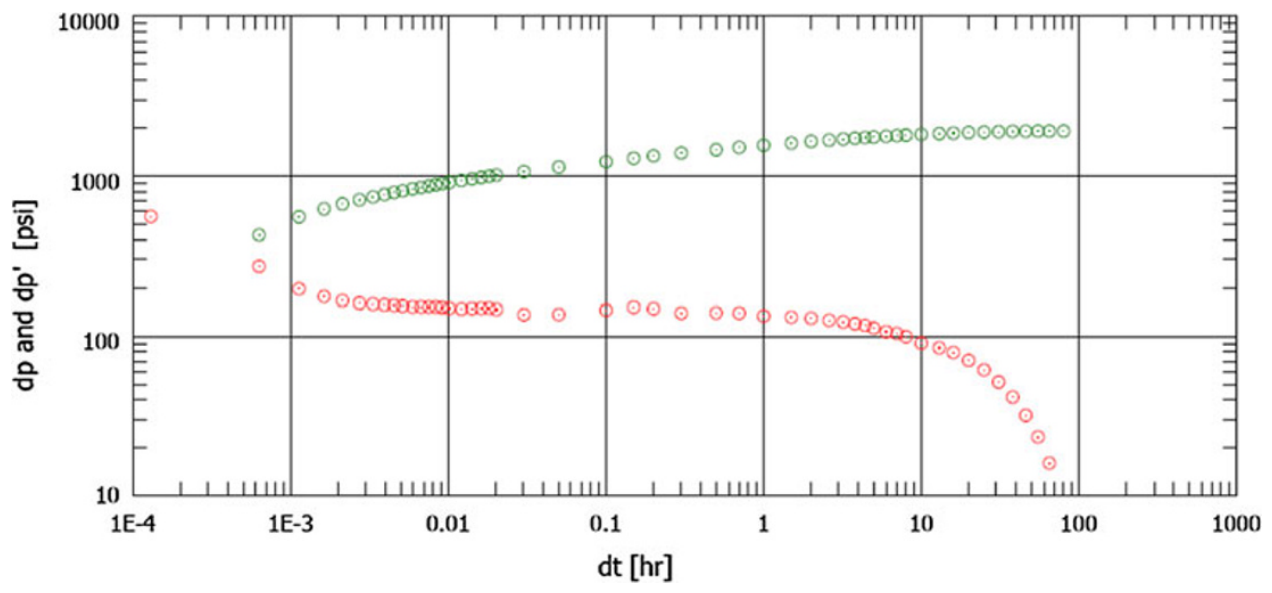

Fig. 11 Pressure and pressure derivative plots for build-up test after 100 days of production

Fig. 7 as marked with two straight lines. The effective mobility of each fluid is calculated by Perrine's method and compared with actual phase mobility in each region. The results of the calculation are listed in the Table 2 . The early time straight line reflects the properties of first closer region to the wellbore with water saturation 0.2 , while the late time straight line does not match the water saturation of 0.5 far from the wellbore.

Figure 8 shows the semi-log plot of the build-up test after 100 days of production. In this case, only one straight line exists. In order to find the reasons of this behavior, the changes of oil saturation in several grid blocks versus production time were plotted in Fig. 9. This figure reveals that after about 95 days of production, oil saturation will become uniform throughout the reservoir. Therefore, there is no saturation variation to be detected by build-up test.

Pressure derivative analysis

Figure 10 presents pressure derivative behavior for buildup test after 50 days of production with a constant rate $1,000 \mathrm{bbl} /$ day. The unusual behavior can be observed again here. As it has been expressed, this abnormal increase in the pressure and pressure derivate curves occurred due to changes of mobility in the region where the water saturation of the reservoir changes from 0.2 to 0.5 . Figure 11 shows pressure derivative build-up curve after 100 days of production. In this case, fluid saturation is uniform throughout the reservoir. Therefore, the pressure derivative responses are just effects by the outer closed boundary at the late time.

\section{Conclusions}

We developed pressure transient formulation for reservoirs with non-uniform fluid saturations. Non-uniform fluid saturation affects pressure and pressure derivative at the wellbore owing to sudden changes of total mobility and flow rate at the vicinity of wellbore. For example, under multiphase flow condition, pressure derivative experienced a transitional region in which pressure goes up. This region is controlled by the total mobility change in the reservoir and cannot be used for interpretation and analysis. In addition, non-uniform fluid saturation distribution in the reservoir causes rapid pressure decline in drawdown similar to the effects of boundaries, e.g. faults. It is then important to recognize the true process, i.e. fault or nonuniform fluid distribution.

Acknowledgments The authors would like to thank Dr. FarzamJavadpour, Dr. Raghavan and Dr. Al-Khalifa for their constructive guides and be grateful to Schlumberger for providing softwares (ECLIPSE 100 and Well Test 200) to carry out this study.

Open Access This article is distributed under the terms of the Creative Commons Attribution License which permits any use, distribution, and reproduction in any medium, provided the original author(s) and the source are credited.

\section{References}

Al-Khalifah-J.A, Aziz. K, Horne RN (1987) A new approach to multiphase well test analysis. SPE: 16743

Al-Khalifah JA (1988) Determination of absolute and relative permeability using well test analysis. Ph.D. dissertation, University of Stanford

Ayan C, Lee WJ (1986) The effects of multiphase flow on the interpretation of buildup tests. Paper SPE 15537 presented at the 61st Annual Technical Conference and Exhibition, New Orleans, LA, 5-8 October 1986

Chu WC, Reynolds AC, Raghavan R (1986) Pressure transient analysis of two-phase flow problems. SPE Form Eval 1(2):151-164

ECLIPSE 100 Version (2005) Technical description. Schlumberger GeoQuest Reservoir Technologies, Houston

Kazemi H (1975) A reservoir simulator for studying productivity variation and transient behavior of a well in a reservoir undergoing gas evolution. Trans AIME 259:1401-1412 
Martine JC (1959) Simplified equations of flow in gas drive reservoirs and the theoretical foundation of multiphase pressure buildup analysis: petroleum transactions. AIME 216:321-323

Perrine RL (1956) Analysis of pressure buildup curves: drilling and production practice. API, 482-509

Raghavan R (1976) Well test analysis: wells producing by solution gas drive wells. Soc Pet Eng J 16:196-208

Raghavan R (1989) Well test analysis for multiphase flow. SPE Form Eval 4(4):585-594

Raghavan R (2010) A note on the theoretical foundations for multiphase pressure analysis for flow in porous media. J Pet Sci Eng 68:81-88
Saphir 4.02 Version (2004) Kappa engineering, petroleum exploration and production software, Houston

Stehfest H (1970) Algorithm 368, numerical inversion of Laplace transforms. Communications of the ACM13, No.1,47-049

Thompson LG, Reynolds AC (1997) Well testing for radially heterogeneous reservoirs under single and multiphase flow conditions. SPE Form Eval 12:57-64

Weller WT (1966) Reservoir performance during two-phase flow. J Pet Tech: 240-246

Zheng S, Xu W (2010) Calibration of fluid model using multiphase well test data for improved history matching. J Pet Sci Eng 75:168-177 